\title{
Relationship between Gross Domestic Product and Accident in China
}

\author{
Rujun Wang ${ }^{\mathrm{a}}$, Jinqiu Gong ${ }^{\mathrm{b}}$, Yu Wang ${ }^{\mathrm{d}}$, Haodong Chen ${ }^{\mathrm{b}}$, Sining Chen ${ }^{\mathrm{a}}$, Qingsong \\ Wang ${ }^{\text {b, }}$ \\ ${ }^{a}$ China Academy of Safety Science and Technology, Beijing 100012, P.R. China \\ ${ }^{\mathrm{b}}$ State Key Laboratory of Fire Science, University of Science and Technology of China, \\ Hefei 230026, P.R. China \\ ${ }^{\mathrm{c}}$ Collaborative Innovation Center for Urban Public Safety, Anhui Province, Hefei \\ 230026, P.R. China \\ ${ }^{\mathrm{d}}$ Department of Civil \& Environmental Engineering, National University of Singapore, \\ Singapore 117576, Singapore \\ Qingsong Wang (Corresponding author) \\ Tel.: +86-551-6360-6455Ｅ-mail: pinew@ustc.edu.cn
}

Received: January 9, 2016 Accepted: January 24, 2017 Published: February 13, 2017

doi:10.5296/jss.v3i1.10571 URL: http://dx.doi.org/10.5296/jss.v3i1.10571

\begin{abstract}
The accident and death data from 2002 to 2015 were obtained from State Administration of Work Safety of China to investigate the relationship between gross domestic product (GDP) and accident. The statistical analysis shows that the accident, death and the death rate of per hundred million yuan present an exponential decreasing trend with the increase of national GDP. The chemical accident data in different provinces were further analyzed. It shows that the dangerous chemical accidents primarily distribute in the regions with better economic development, so more safety measures should be taken to prevent the accidents during economic development. In addition, the next three years of accidents were predicted based on auto-regressive integrated moving average (ARIMA) model. The results show that the following two years accidents predicted will be reduced by $4.3 \%$ and $6.5 \%$ than the last year.
\end{abstract}

Keywords: China insurance industry, Foreign fund, Challenge

\section{Introduction}

The average annual rate of economic growth in China is $9.69 \%$ from 2002 to 2015 . With the rapid economic development, China is struggling to balance the demands of a booming 
economy with growing accidents concerns. A large number of severe accidents occur in China every year, which brings some physical and social damages to the whole society [1]. In 2015, there are still some severe accidents occurred in China, one of which occurred at a chemical warehouse in city of Tianjin on 12 August 2015 and caused 165 deaths and loss of 6.866 billion yuan.

Economic development can improve quality of our lives. However, accidents can cause a lot of loss both in economy and casualty. Therefore, it is necessary to investigate the health and safety system to prevent such accidents [2]. In the process of economy development, the accidents are always difficult to avoid. The governmental officials at all levels feel great pressure to maintain a high rate of gross domestic product (GDP) growth while avoiding accidents. In most cases, they put the economic development on priority, but not on the environmental, health and safety issues [3, 4]. Revealing the inherent relation between economy and accidents can help to reduce the accidents. Therefore, it is necessary to study the relationship between accident and economy growth. Kopits and Cropper [5], and Yannis [6] studied the relationship between traffic fatalities and economic growth. Carrion-i-Silvestre et al. [7] analyzed the stationary of the real per capita health care expenditure (HCE) and real per capita GDP. What is more, Sülkü and Caner [8] investigated the long-run relationship among per capita GDP, per capita health expenditures and population growth rate. Halıc1-Tülüce et al. [9] revealed the relationship between health expenditure and economic growth. van Dijk et al. [10] revealed the importance of occupational safety and health (OSH). However, few studies were reported on the relationship between GDP and accident. As GDP is the key index to express the economic growth, it is quite important both for the development and accident prevention. The relationship between accident and the GDP was studied based on the statistical data of economy and accident of China in this work.

\section{Data collection}

In China, there are totally 31 provinces, autonomous regions, and municipalities, while they present significant differences in economic development, accidents and populations among the regions, which form a valuable data base to study the inherent relationship between GDP and accident.

An accident is a detrimental event that occurs unexpectedly and unintentionally. Physical damages include unintended collisions or falls, being injured by touching something sharp, hot, electric, or ingesting poison. The accident data were cited from the website of State Administration of Work Safety (SAWS). In the present work, all kinds of events are considered, such as industrial accidents, traffic accidents. The death used in this work refers the total number that occurred in that year - including from natural causes, fire, traffic, crashes, etc.

The population and economy data were adopted from the website of National Bureau of Statistics of China. Other related data were cited from websites. GDP is usually calculated on an annual basis, but is the monetary value of all the finished goods and services produced within a country's borders in a specific time period. It includes all of private and public 
consumption, government outlays, investments and exports less imports that occur within a defined territory. It can be expressed as:

$$
\mathrm{GDP}=\mathrm{C}+\mathrm{G}+\mathrm{I}+\mathrm{NX}
$$

where $\mathrm{C}$ is equal to all private consumption or consumer spending in the national economy, $\mathrm{G}$ is the sum of government spending, $I$ is the sum of all the country's businesses spending on capital, NX denotes the nation's total net exports and is equal to the total exports minus total imports (NX = exports - imports).

\section{Analysis and Discussion}

\subsection{Relationship between Accident and Casualty}

Figure 1 shows the relationship between accidents and deaths from 2002 to 2015 based on the data of the whole country. It can be seen that the number of death and accident decreases year by year. In addition, there is an agreement between the decreasing trends of two parameters, which means that if more accidents occur, it will cause more deaths inescapably. Under that condition, some measures should be taken on safety management to control the accidental casualties. Accidents show a declining trend from 2002 to 2015, and accordingly the number of death drops with accidents synchronously.

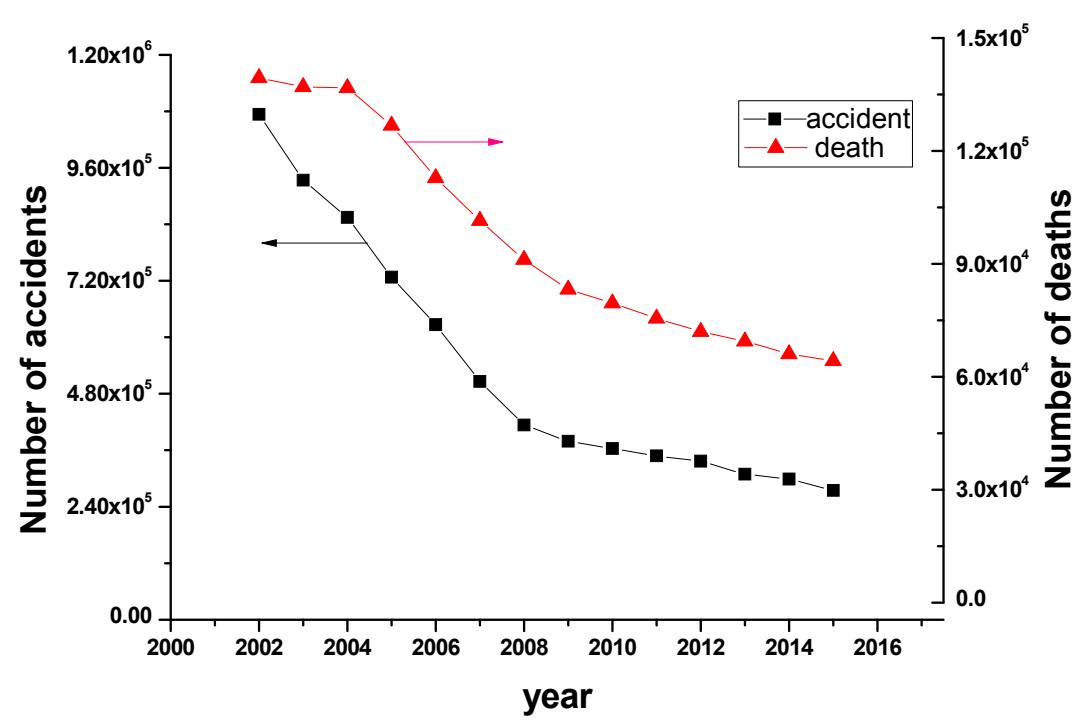

Fig. 1 The accident and death vs. year from 2002 to 2015 in China

\subsection{Relationship between accident, death and GDP from years 2002 to 2015}

Figure 2 shows the GDP changing trend from 2002 to 2015. It can be seen that GDP increases rapidly from 2002 to 2015. Fig. 3 and Fig. 4 are the curves of accidents, deaths and deaths rate of per hundred million yuan vs. GDP from 2002 to 2015 in China. In the figures, the horizontal projections to $y$ axis are the number of accidents, the number of death and deaths rate of per hundred million yuan respectively. Here the GDP refers to the total GDP of China. Deaths rate of per hundred million yuan means the number of deaths caused by accidents for 
every one hundred million yuan output. As a statistic index, it can also be used to weigh the relation between accident and GDP.

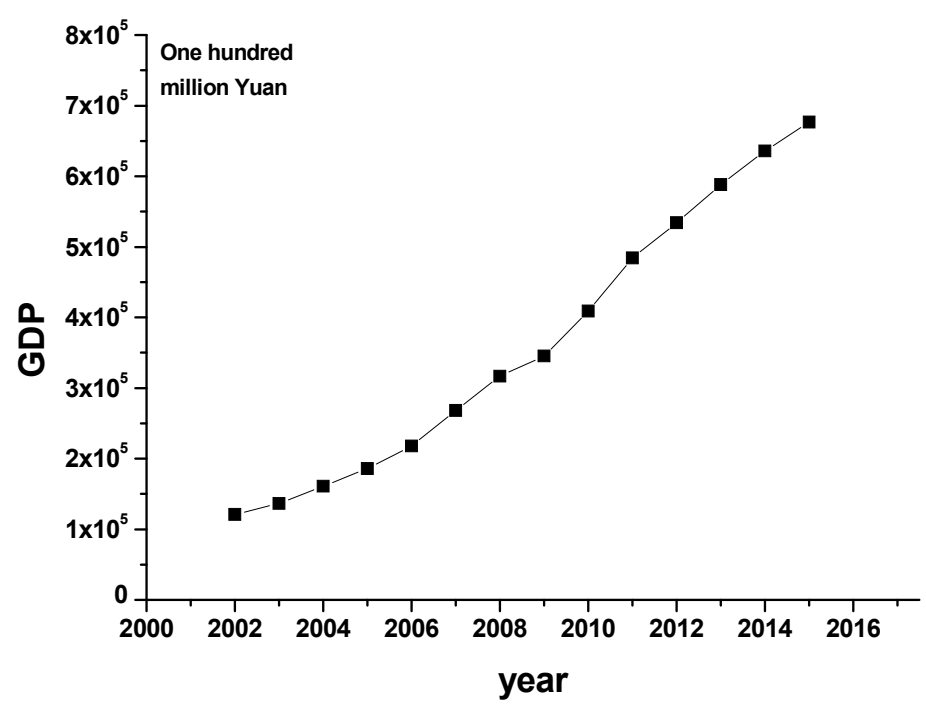

Fig. 2 The GDP vs. year from 2002 to 2015

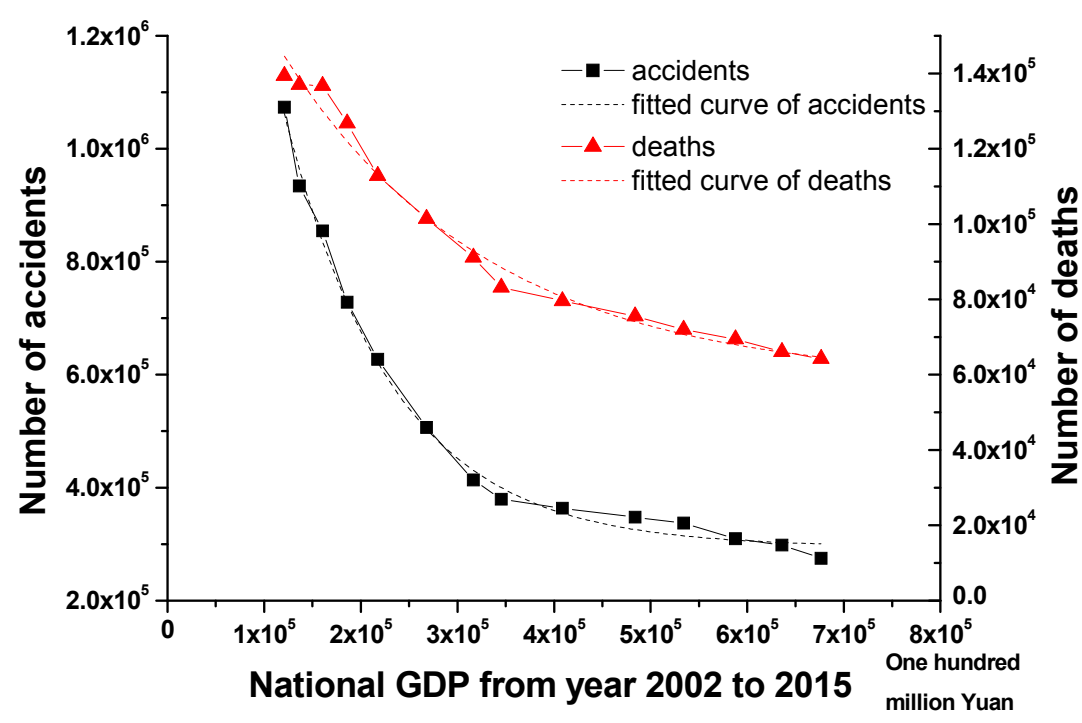

Fig. 3 The accidents and deaths vs. GDP from 2002 to 2015 


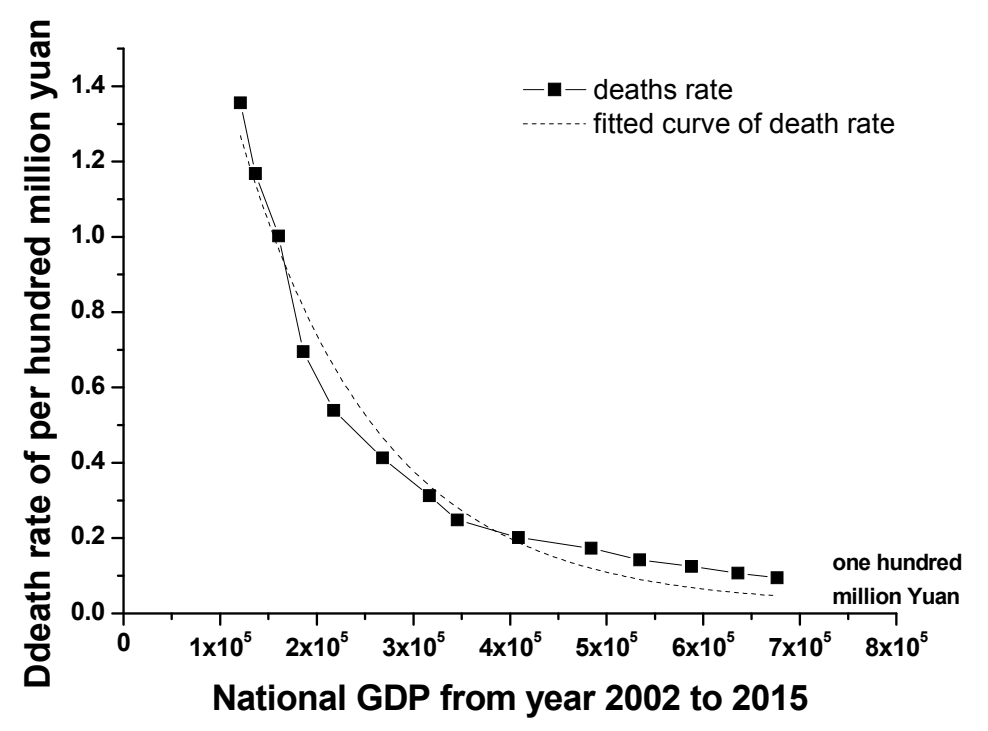

Fig. 4 The death rate of per hundred million yuan vs. GDP from 2002 to 2015

By fitting the data in figures, the nonlinear equations are given as follows:

Accident-GDP relationship:

$$
\alpha=2.24 \times 10^{6} e^{-\frac{G D P}{112939.957}}+294854.354
$$

Death-GDP relationship:

$$
\beta=1.52 \times 10^{5} e^{-\frac{G D P}{213573.419}}+58284.152
$$

Deaths rate-GDP relationship:

$$
\gamma=2.93 e^{-\frac{G D P}{14335.179}}+0.021
$$

where $\alpha, \beta$ and $\gamma$ are the number of accident, the number of death and death rate of per hundred million yuan, respectively. While the fitted nonlinear tend means that the accidents, deaths and death rate of per hundred million yuan get smaller with the GDP increase. All the figures show the decreasing exponential relations with increasing national GDP year by year, which indicates that in the development of the national GDP these years, at the same time, safety condition is becoming increasingly better.

\subsection{Relations between accidents and GDP from provinces in China}

A chemical accident is the unintentional release of one or more hazardous substances which could harm human health and the environment. Such events include fires, explosions, leakages or releases of toxic or hazardous materials that can cause people illness, injury, disability, and even death. The accidents of dangerous chemical compared with other types of accidents, normally account for a large proportion of the accidental statistics. Therefore, 
relation between dangerous chemical accidents with GDP was selected as a representative, which are collected from different regions in China. Fig. 5 shows chemical accident and GDP of different provinces in the year of 2011. It can be seen that there are similar correlations between dangerous chemical accidents and GDP for different regions in China. In addition, the chemical accidents primarily distribute in Jiangsu, Zhejiang, Shandong and Guangdong provinces, where GDP outputs are larger than other regions. Likewise, the accidents in regions such as Xizang, Qinghai occur less frequently, which is attributed to their GDP outputs. This phenomenon relates to the distribution of chemical enterprises in the whole country. Therefore, though the number of accident is decreasing with the increase of GDP from the lever of the whole country. It is noted that developed provinces should pay more attention to safety production, and being aware of balancing the relationship between GDP and safety issues.

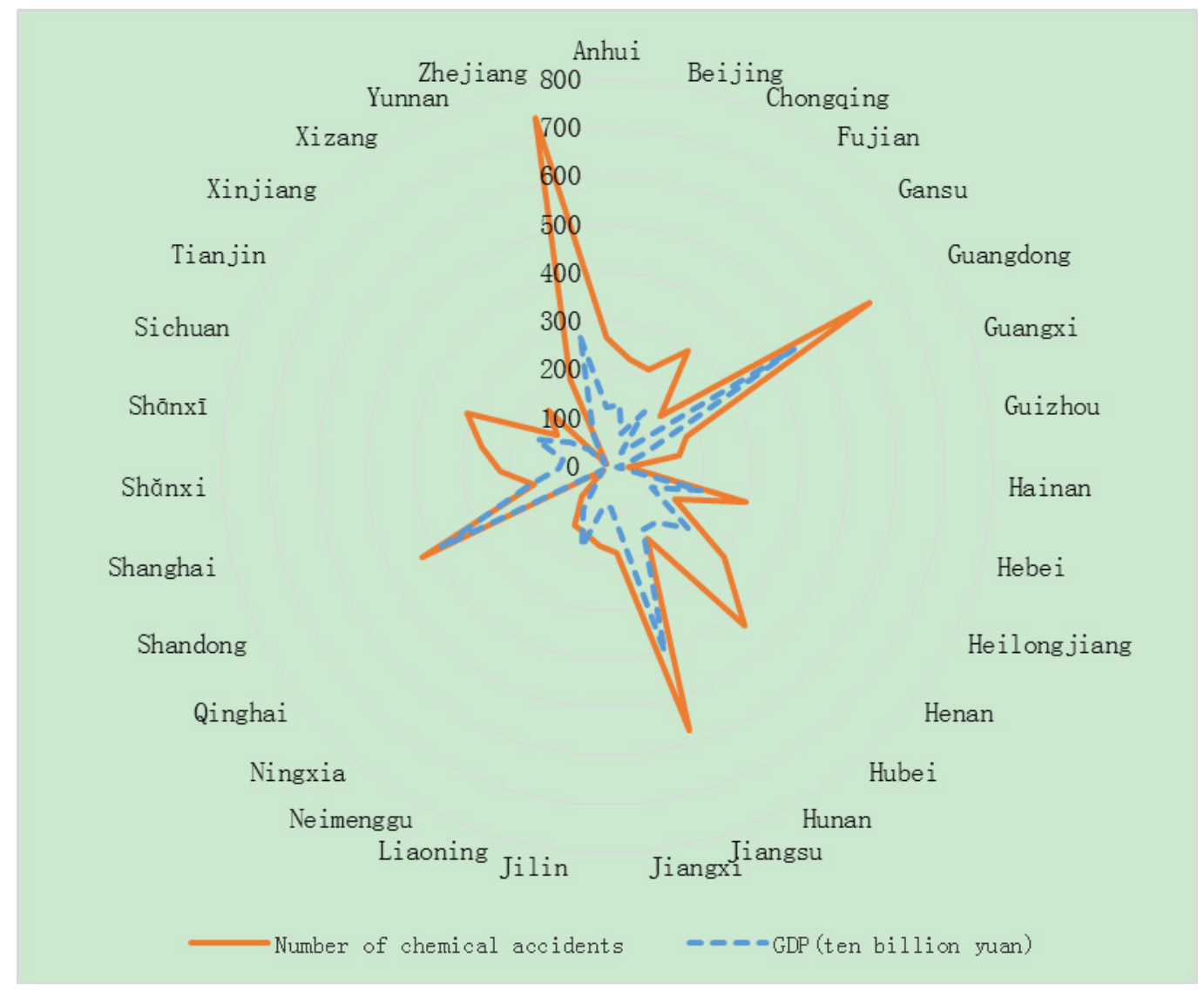

Fig. 5 The chemical accidents and GDP of different provinces in 2011

\section{Forecast on accidents and GDP based on ARIMA model}

Auto-regressive integrated moving average (ARIMA) model is one of the most commonly used models in time series analysis, which provides a set of effective prediction technologies. It regards a sequence of data formed by forecast indexes over time as a random sequence with their dependence on the continuity of original data. By using this model, the future accidents can be predicted based on the history data, as shown in Fig. 6. Accident and GDP are selected as variables as the function of time from 2002 to 2017. Based on the ARIMA model, the GDP and growth rate of year 2017 can be predicted. It can be seen that the GDP shows a slight 


\section{Macrothink

increase, and the growth rate is approximately $6.9 \%$ than the last year. On the other hand, the number of accidents continues to decrease, respectively, reduced by $4.3 \%$ and $6.5 \%$ than the last year. According to this prediction, although there are relative errors to some degree, it agrees well with the above conclusion that accident shows the decreasing trend with national GDP increasing year by year.

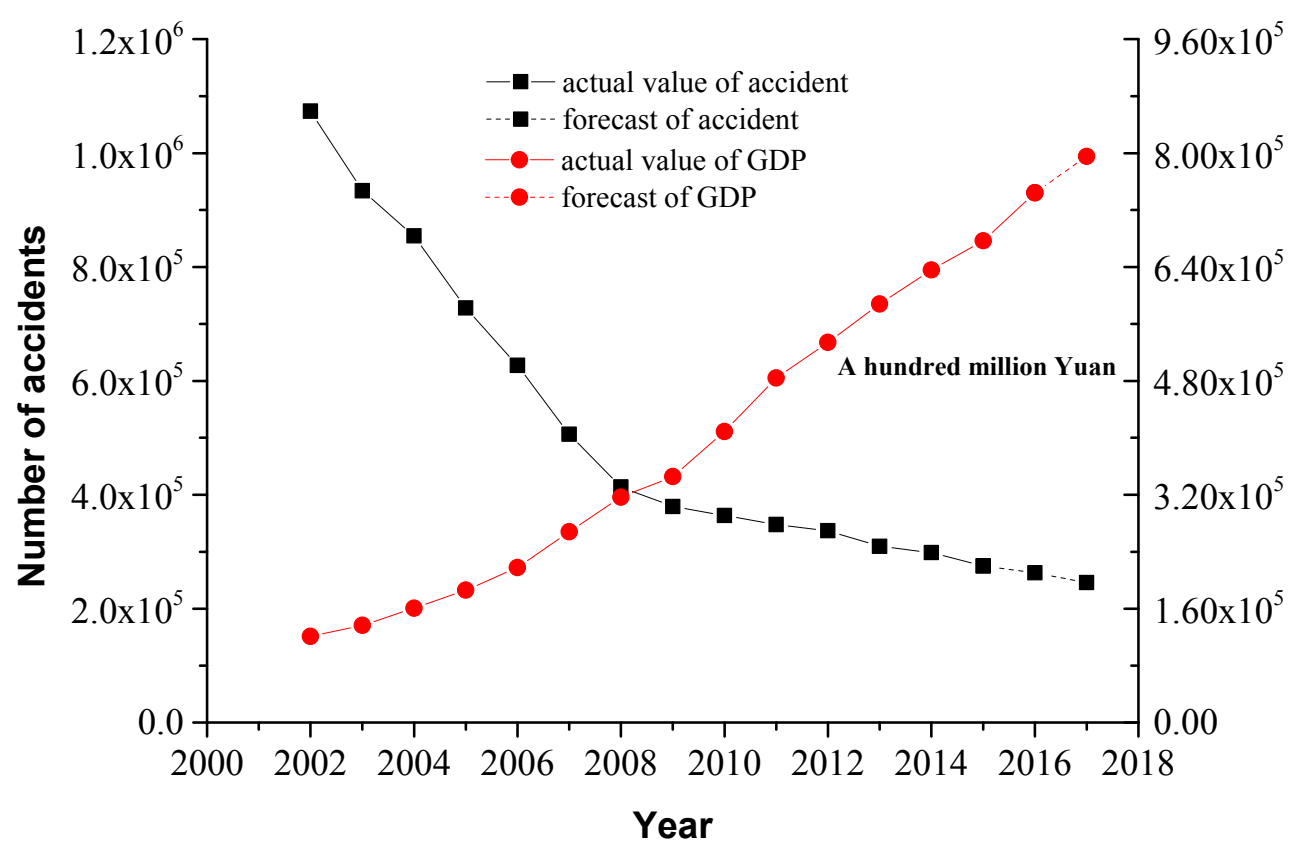

Fig. 6 The forecast on GDP and accident $v s$ time from 2002 to 2017

\section{Conclusions}

At present, the economic situation becomes better, and at the same time, the safety draws increasing attention and maintains well through the effort of official governments. The statistic data show that the death presents incremental nonlinear relation with the accidents. The accident, death and the death rate of per hundred million yuan present the exponential decreasing trend as national GDP increases year by year. Besides, the chemical accidents from developed provinces were compared with other areas in China. The analysis indicates that the majority of chemical accidents distribute in developed provinces. In addition, according to ARIMA prediction model, the accident was predicted that it inversely proportional to the GDP of whole country.

\section{Acknowledgements}

This work is supported by the Fundamental Research Funds for the Central Universities (No. WK2320000034). Dr. Q.S Wang is supported by Youth Innovation Promotion Association CAS (No.2013286). 


\section{References}

[1] Wei, J., \& Lu, S. (2015). Investigation and penalty on major industrial accidents in China: The influence of environmental pressures. Safety Science, 76, 32-41. http://dx.doi.org/10.1016/j.ssci.2015.02.006

[2] Shalini, R. T. (2009). Economic cost of occupational accidents: Evidence from a small island economy. Safety Science, 47, 973-979. http://dx.doi.org/10.1016/j.ssci.2008.10.021

[3] Arrow, K. J., Cropper, M. L., Eads, G. C., \& Hahn, R. W. (1996). Is there a role for benefit-cost analysis in environmental, health, and safety regulation? Science, 272, 221. https://doi.org/10.1017/S1355770X97220164

[4] Rodgers, S. H. (1992). Increasing productivity and profit through health and safety. Case studies in successful occupational health and safety practice. Journal of Occupational Rehabilitation, 2, 51-51. doi:10.1007/BF01078931

[5] Kopits, E. \& Cropper, M. (20015). Traffic fatalities and economic growth. Accident analysis \& prevention, 37, 169-178. http://dx.doi.org/10.1016/j.aap.2004.04.006

[6] Yannis, G., Papadimitriou, E., \& Folla, K. (2014). Effect of GDP changes on road traffic fatalities. Safety Science, 63, 42-49. http://dx.doi.org/10.1016/j.ssci.2013.10.017

[7] Carrion-i-Silvestre, J. L. (2005). Health care expenditure and GDP: Are they broken stationary? Journal of Health Economics, 24, 839-854. http://dx.doi.org/10.1016/j.jhealeco.2005.01.001

[8] Sülkü, S. N., \& Caner, A. (2011). Health care expenditures and gross domestic product: the Turkish case. The European Journal of Health Economics, 12, 29-38. doi:10.1007/s10198-010-0221-y

[9] Halıc1-Tülüce, N. S., Doğan, İ., \& Dumrul, C. (2016). Is income relevant for health expenditure and economic growth nexus? International Journal of Health Economics and Management, 16, 23-49. doi:10.1007/s10754-015-9179-8

[10] van Dijk, F. J., Bubas, M., \& Smits, P. B. (2015). Evaluation Studies on Education in Occupational Safety and Health: Inspiration for Developing Economies. Annals of Global Health, 81, 548-560. http://dx.doi.org/10.1016/j.aogh.2015.08.023

\section{Copyright Disclaimer}

Copyright for this article is retained by the author(s), with first publication rights granted to the journal.

This is an open-access article distributed under the terms and conditions of the Creative Commons Attribution license (http://creativecommons.org/licenses/by/3.0/). 